\title{
Thrusters physical model formalization with regard to situational and identification factors of motion modes
}

\author{
Vitalii Budashko \\ National University "Odessa Maritime \\ Academy" \\ $N U$ "OMA" \\ Odesa, Ukraine \\ bvv@te.net.ua
}

\begin{abstract}
Within the framework of the research of diagnostics and prediction of technical state of ship power plants (SPP) of combined propulsion complexes (CPC) dependences of correcting factors influencing components of thrusts and moments, proportional dimensions of model and real thrusts (THRs), tied to the original geometry were obtained. This was done by formalizing the physical model of the azimuth thruster with the means of identifying the degradation effects on the flow lines of the propellers by methods of computational hydrodynamics. The technique of improving the structure of the mathematical models of the SPP CPC according to experimental studies by measuring the input and output parametric coordinates of the THRs CPC of a vessel operating in the dynamic positioning mode is announced.
\end{abstract}

Keywords-thruster, physical model, mathematical modeling, combined propulsion complexes, formalization.

\section{Introduction}

During investigation of processes in the ship power plants (SPP) combined propulsion complexes (CPC) critical step for check adequacy mathematical and simulation models there is to create and perfection of physical models these SPP. The maximum range of the practical part of the research work they allow you to realize.

Creating physical models of various objects is to comply with the hydrodynamic similarity there is the main problem in now. In accordance with the Kirpichev-Gukhman's theorem of similarity hydrodynamic action will be similar if they:

- $\quad$ the system of differential equations are describes;

- $\quad$ similar conditions of uniqueness are has;

- numerically equal similarity criteria are has $[1,2]$.

In particular, compliance with the geometric similarity to bridge independent of the size of the hydrodynamic properties is not enough.

\section{Purpose of work}

As you know the main criteria of hydrodynamic similarity criterion is Froude, Reynolds, Euler and Strouhal. Into account the effect of various physical forces acting on physical model and the real object they are taking, as well as characterize the inertial-hydrodynamic forces generated for unsteady fluid motion. The practical and physical impossibility of simultaneous execution conditions complete similarity makes us look for particular criteria of similarity, expressing conditions of similarity when the prevailing acts as one of the active forces $[3,4]$.
Depending on the tasks carried out by the ship, increasing the introduction on board vessels of various types of thrusters and azimuth propeller-rudder systems (AZIPOD), allows the use of dynamic position (DP) of three types $[5,6]$. In any event, the creation of a physical model of the ship, a mode-DP, allows o consider hydrodynamic similarity with one of the predominant influence of the applied forces.

It is impossible to simultaneously satisfy the criteria are Reynolds and Froude for the same environment in the model and

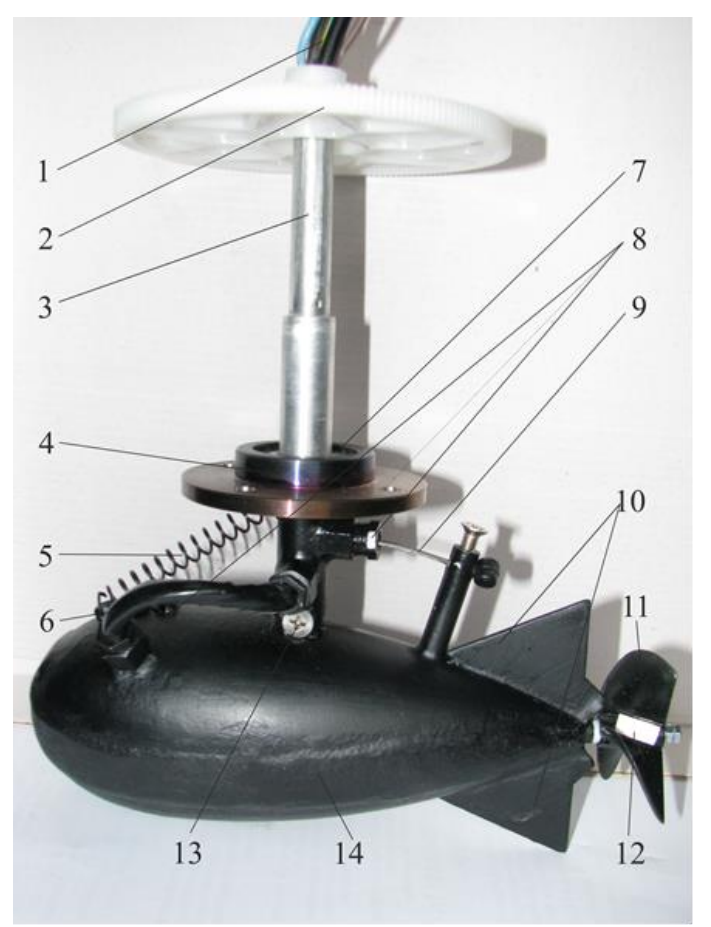

Figure 1. Physical model of the steering gear with two degrees of freedom: 1 - power cable rowing AD and cable to change the angle of inclination; 2 - the driving gear of the drive of turn of the baller; 3 - baller; 4 - bearing shield; 5 - the spring of feedback about change of an inclination; 6 - power cable; 7 - the bearing; 8 - stuffing boxes; 9 - cable for changing the angle of inclination; 10 - stabilization wings; 11 - FPP; 12 - is the fluorescent label for remote measurement of FPP rotation speed; 13 - connection point of the baller with the housing of the thruster; $14-$ is the thruster housing with the thruster located in the middle. 
in nature. Anyway, when vessel work in DP and your velocity relative to the water surface is equal to zero, is predominant Froude criteria, unlike Reynolds. To eat, there is a hydraulic process of the interaction of a fixed-foot boat with waves and currents created by propellers $[7,8]$.

If the environment of the experiment will be different from the full-scale, one of the defining criteria should be the Archimedes criterion. For individual thruster or AZIPOD that operate with each other and to the vessel as a whole by means of the propeller thrust criterion Strouhal will trolled as a function of the Reynolds number lying in the range $200<\operatorname{Re}<200000$. This constant Strouhal number: $\mathrm{Sh}=0.2 \div 0.3$. For difference between the propeller thrust, the nature of this dependence is standing in for all flow conditions in the housing above a wide range of Reynolds numbers. This reflects the dominant role of vorticity in the poop area bad streamlined hull (limiting case - is cross-action to the flow) in the formation of the pressure field on its surface, and hence the energy losses.

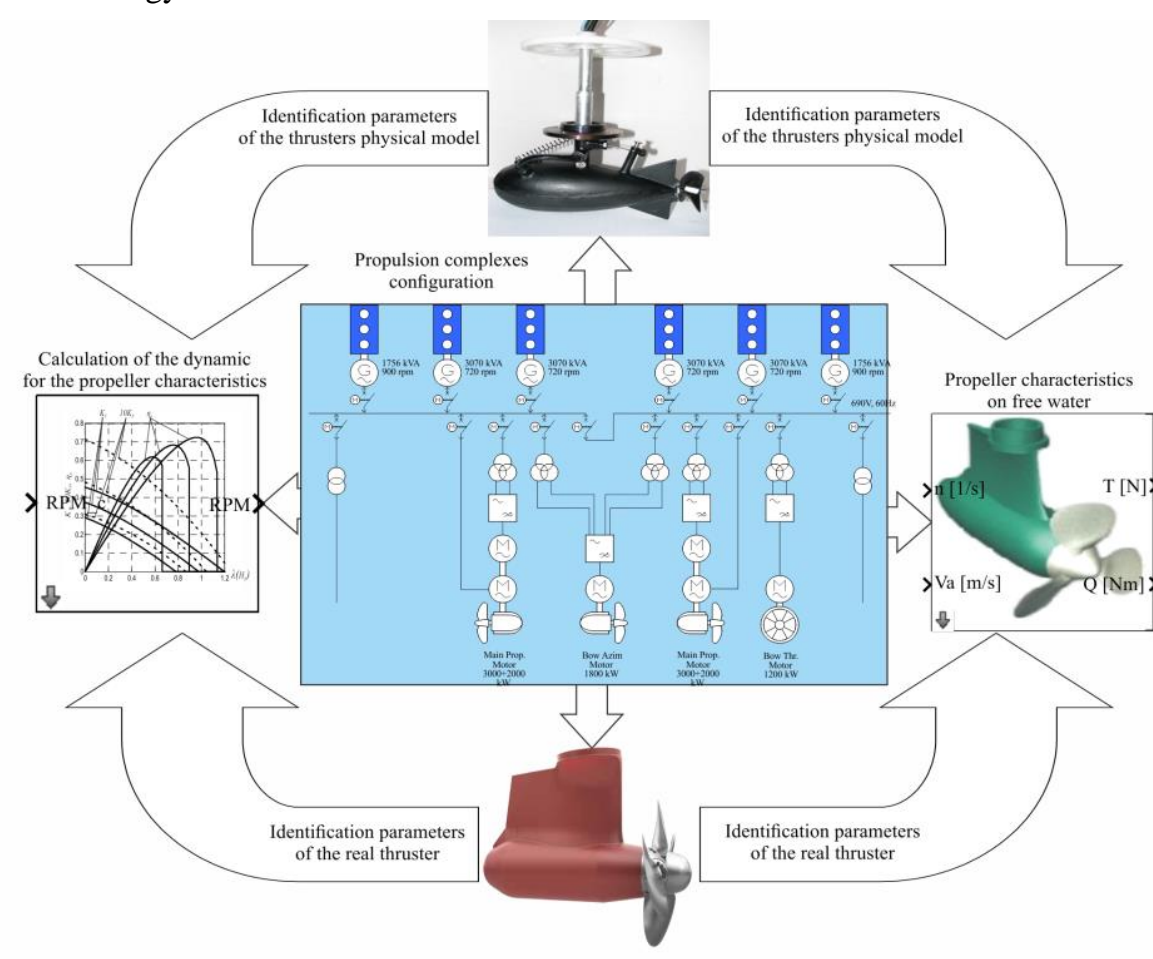

Figure 2. Visualization of the process of formalization for thrusters physical models with determination of the configuration for the combined propulsion complex

Euler's criterion for the retractable or tunnel thrusters can be decisive. In turn, the latter requires accounting criteria as defined in the Strouhal.

Based on the above, and given the fact that the geometric similarity observed, and the type, shape and number of propeller blades is not determinative criteria for individual thruster or AZIPOD as part of full-scale SPP CPC, you can build him quite adequate physical model.

\section{CONTENTS AND RESULTS OF THE RESEARCH}

We accept the assumption that all of the electrical and thermal engines will be in full-scale-like, and for them to be sustained following constants: lu - zoom speeds; lt - time scale; lq scale mass forces; le - length scale and a linear scale; for the environment: $\ln$ - coefficient scale kinematic viscosity and $1 r$ scale density; and for the tunnel or retractable thrusters: lp - the scale of the pressure forces.

In accordance with the le, for the type of propeller, once identified the main-body model measures the rate of displacement of the vessel $\mathrm{D}=100,000$ tons and RMS-velocity movement in seawater $v=22$ knots. Arrange housing thruster type Azipod as the streamlined nacelle with proportional sizes, with stern device and baller is designed (Fig. 1).

Keeping velocity scale lu were selected: reduction gear for the on-gate rudder for speed rudder from side to side about $2 \% \mathrm{sec}$ and an electric motor with reduction gear for driving screws on $0 \div 300 \mathrm{rev} / \mathrm{min}$, and to meet the scale of the mass forces lq housing AZIPOD model in proportion to the leadfilled was weighted.

The process of formalization of physical models is given Fig. 2. Using the full set of parameters here is faster in exceptional cases than in one of the automatic modes. At the same time, the decisionmaker is guided by the accumulated experience and systematic typical situational factors with which current situations arise.

Motor Hobbywing QUICRUN Sensored Burshless Combo 13.5T Motor + 60A ESC 2500KV RC CAR - brushless three-phase low-resistance high-reflex with the following characteristics: $\mathrm{RPM} /$ Volt $(\mathrm{KV})$ - 2500; rated current 60A; peak current - 380A; Model: QUICRUN-3650-25.5T; LiPo Cells: 2 3S; outer diameter/length: 36 mm/52,8 mm; R.: 0,1; No-load Current: 1.1; Diameter of the Shaft: $3.17 \mathrm{~mm}$; Poles: 2.

Specifications of ESC: Brand: SkyRC; Motor compatible: Brushless sensor/sensorless ESC Car compatible:1/10 and 1/12 Buggy and Touring Car Power supply: 2-3S LiPo battery, 4-9S NiMh battery BEC output: 6V/3A; Constant current: 60A; Burst current: 380A; Resistance: 0.0007 Ohm; Fan: 8V/0.2A, Max 12.6V.

Instructions for use, connection and programming the controller, as well as span of control channels when you first start a new regulator, using a controller with a new receiver or when changing the neutral position of the transmitter, as well as other parameters are given in $[9,10]$.

There are wiring diagrams rudder servo rotation, exuding nick-power and controls the electric drive of the shaft and a table 
selection controller mode, depending on the requirements of technological process [11-13].

One of the most promising concepts SPP CPC is a hybrid board installation with contra-rotating propellers (Contra-Rotating Pod, CRP), operating in DP mode. It is dominated by the gravitational force and the law of Froude similarity, which is necessary for compliance with the equality of numbers for the model and nature, i.e., FrM $=\mathrm{FrH}$ and similarity criteria must be expressed in terms specific to the mode value.

When the water flow around the hull as the characteristic measure of the linear time-selected length of the vessel between perpendiculars at the waterline and the precipitate in the flow direction, and as the characteristic velocity - flow rate of attack.

Froude similarity criteria for our case we get from the general criterion of hydrodynamic similarity of Newton, substituting in this equation the gravity, $\mathrm{G}=\mathrm{mg}$ :

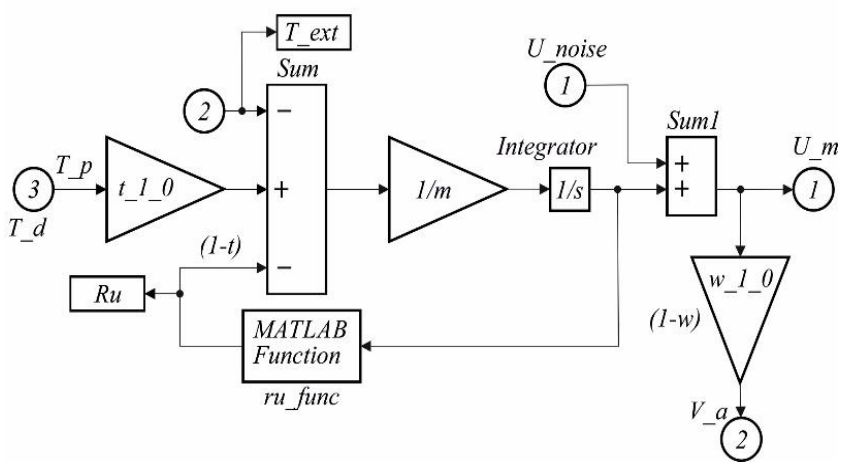

Figure 3. - Model ship dynamics: $T \_d-$ thrust of propeller; $t \_1 \_0=1-\mathrm{t}=$ the average value of the thrust deduction coefficient, p.u., measured data for the proper model ship; $T \_$ext - thrust of the external Force; $m=$ $10009 * 1025$ (displacement*the specific gravity of marine water) + weight of the load; $U \_$noise - noise of the speed vessel; $R u_{-} f u n c$ - the function of calculating the resistance movement of the ship $(R u) ; w_{-} 1 \_0=1-w=$ the average value of the wake fraction deduction coefficient, p.u., for the corresponding model ship; $U_{-} m$ - the ship's speed,

$\frac{v_{S}^{2}}{g_{S} \cdot l_{S}}=\frac{v_{M}^{2}}{g_{M} \cdot l_{M}}$,

where: $\mathrm{v}$ - the speed of the incoming flow, $\mathrm{m} / \mathrm{sec} ; \mathrm{g}-$ gravity, $\mathrm{m} / \mathrm{sec} 2 ; 1$ - length, $\mathrm{m}$; respectively $(\mathrm{S})$ - of the ship and (M) - of the model.

From equation (1) is necessary to obtain the basic parameters of any emerging flows, taking into account the extent of similarity. We calculate at what rate are based, thrust and torque for the model and ship are modeled on the law of Froude.

If the field conditions and the conditions of the test model the acceleration of gravity $\mathrm{gS} \neq \mathrm{gM}$, then (1) follows:

$\frac{v_{S}}{v_{M}}=\sqrt{\frac{l_{S} \cdot \rho_{1}}{l_{M} \cdot \rho_{2}}}=\sqrt{\lambda_{S M}}$, where $\rho 1, \rho 2$ - density of the environments, $\mathrm{kg} / \mathrm{m} 3$, since the rate for the model of flow of water should be reduced to $\sqrt{\lambda_{S M}}$ , provided Archimedes criterion for natural environment and simulation environment.

Accounting cavitation is carried out in compliance with the criteria of similarity Fr, Re and equality of the numbers Eu for the model and vessel.

Thus, the thrust of propeller for model and the vessel should be in the relationship:

$$
\frac{T_{S}}{T_{M}}=\frac{n_{S} \cdot v_{S}}{n_{M} \cdot v_{M}}=\lambda_{S M}^{2} \sqrt{\lambda_{S M}}=\lambda_{S M}^{2,5},
$$

where $\mathrm{nS}, \mathrm{nM}-\mathrm{RPM}$ of propellers shaft, RPM/min; since the thrust of the ship propeller TS, then at a lower $I S M$ times model, propeller thrust must be less to $\lambda_{S M}^{2,5}$ times subject to the criterion of geometrical similarity.

The ratio of the moments on the shafts of the propeller, and consequently consumed by drive motors capacity, taking into account the ratio of (1) and (2) is equal to:

$$
\frac{Q_{S}}{Q_{M}}=\frac{D_{S} \cdot v_{S}}{D_{M} \cdot v_{M}}=\lambda_{S M}^{2,5} \sqrt{\lambda_{S M}}=\lambda_{S M}^{3},
$$

where DS, DM - diameter of propeller, $\mathrm{m}$.

Similarly, through a linear scale can calculate scale value for the other parameters.

\section{THE RESULTS OF RESEARCH.}

The adequacy of the physical model using MatLab/Simulink was checking, with the help of software Ships_CPC, developed in the framework of research work of the state budget "Concept of technology and ways of improving ship power plants combined propulsion complexes" at the Electromechanics and Electrical Engineering department of National University (Odessa Maritime Academy) (Fig. 3).

If CPP CPC operates in DP, ship model, the so-called m-file "is generated" with computer applications WAMIT (Wave Analysis Massachusetts Institute of Technology) [14-16] and is a functional unit that connects between the result vector of trust tau, for example, six electrical motors of thrusters with three degrees of freedom (3 degrees of Freedom (DOF) control vector) to the output of meter dynamic positioning vessel, where: $\mathrm{u}-$ travel speed, $\mathrm{m} / \mathrm{sec} ; \mathrm{v}$ - speed transverse displacement, $\mathrm{m} / \mathrm{sec} ; \mathrm{r}$ - yawing rate, $\mathrm{rad} / \mathrm{sec}$; $\mathrm{x}-\mathrm{x}$-position, $\mathrm{m}$; $\mathrm{y}-\mathrm{y}$-position, $\mathrm{m}$; psiyawing angle, rad.

\section{ACKNOWLEDGEMENTS}

The author designed and implemented a model in computer laboratory, which is used in study process and permits to solve main tasks of project and exploitation of combined propulsion complexes.

The engineering theory "Controlling system for asynchronous thrust motors" has been developed and implemented in 
practice, methodical recommendation "Ship's electrical drives for DP vessels" and "Ship's automated drives" for courses of laboratory has been published. A tutorial "Power electrical machine for AZIPOD devices" has been published with preliminary recommendation and legalization of Academic council of Odessa National Maritime Academy.

\section{CONCLUSIONS AND RECOMMENDATIONS}

The ratios of the THRs CPC ratios are better correlated with the power ratios than the stepping screw ratios, which gives reason to believe that the efficiency of the SPP CPC's energy efficiency is increased in operational modes and allows the results to be added to the database of decision support systems (DSS) for developers and research new concepts of the SPP CPC's or to modify existing ones [17].

Determining the magnitudes of the stresses attached to the vessel and forming the configuration matrix of the THRs with determining the distance from the point of application of the emphasis of the individual THRs to the projection of the force vector on the plane of motion of the vessel is possible based on the study of the internal properties of the components of SPP CPC's operating in the mode of dynamic positioning relevant identification factors.

The dependence of the correction factors affecting the components of the stops and moments, proportional to the radius of the model and the real THRs, bound to the original geometry, is obtained by formalizing the physical models of the azimuthal THRs with the means of identifying the degradation effects on the flow lines of the rotor screwdrivers [18].

Improvement of structures of mathematical models of SPP CPC's according to experimental studies is possible by measuring the input and output parametric coordinates of the THRs CPC of the vessel operating in the mode of dynamic positioning, with the estimation of the variances of the coefficients of the regression equations, and the construction of the approximate control parameters of the CPC as part of the design of the DSS using orthogonal composite experiment planning, drawing up the appropriate matrix and obtaining the results in the form of a coefficient in the model.

\section{REFERENCES}

[1] Fu, J. Multi-level virtual prototyping of electromechanical actuation system for more electric aircraft [Text] / J. Fu, J.-C. Mare, L. Yu, Y. Fu / Chinese Journal of Aeronautics. - 2018. - V. 31, I. 5. - P. 892-913. ISSN 1000-9361. Doi: 10.1016/j.cja.2017.12.009.

[2] Fu, J. Modelling and simulation of flight control electromechanical actuators with special focus on model architecting, multidisciplinary effects and power flows [Text] / J. Fu, J.-C. Maré, Y. Fu // Chinese Journal of Aeronautics. - 2017. - V. 30, I. 1. - P. 47-65. ISSN 1000-9361. Doi: $10.1016 /$ j.cja.2016.07.006.

[3] Kühnel, N. Implementing an adaptive traffic signal control algorithm in an agent-based transport simulation [Text] / N. Kühnel, T. Thunig, K. Nagel // Procedia Computer Science. - 2018. - V. 130. - P. 894-899. ISSN 1877-0509. Doi: 10.1016/j.procs.2018.04.086.

[4] Budashko, V. V. Design of the three-level multicriterial strategy of hybrid marine power plant control for a combined propulsion complex [Text] / V. V. Budashko / Electrical engineering \& electromechanics. - 2017. №2. - P. 62 - 72. Doi:10.20998/2074-272X.2017.2.10.

[5] Budashko, V. Theoretical-applied aspects of the composition of regression models for combined propulsion complexes based on data of experimental research [Text] / V. Budashko, V. Golikov // EasternEuropean Journal of Enterprise Technologies. - 2017. - V. 4. - № 3(88). - P. 11 - 20. Doi:10.15587/1729-4061.2017.107244.

[6] Budashko, V. Formalization of design for physical model of the azimuth thruster with two degrees of freedom by computational fluid dynamics methods [Text] / V., Budashko // Eastern-European Journal of Enterprise Technologies. - 2017. - V. 3. - № 7(87). - P. 40-49. Doi:10.15587/17294061.2017.101298.

[7] Prabhu, J. J. On the hydrodynamic loading of marine cycloidal propeller during maneuvering [Text] / J.J. Prabhu, A.K. Dash, V. Nagarajan, O.P. Sha // Applied Ocean Research. - 2019. - V. 86. - P. 87-110. ISSN 01411187. Doi: 10.1016/j.apor.2019.02.008

[8] Budashko, V. Decision support system's concept for design of combined propulsion complexes [Text] / V. Budashko, V. Nikolskyi, O. Onishchenko, S. Khniunin / Eastern-European Journal of Enterprise Technologies. - 2016. - V. 3. - № 8(81). - P. 10 - 21 . Doi:10.15587/1729-4061.2016.72543.

[9] Thieme, C. A. Assessing ship risk model applicability to Marine Autonomous Surface Ships [Text] / C. A. Thieme, I. B. Utne, S. Haugen // Ocean Engineering. - 2018. - V. 165. - P. 140-154. ISSN 0029-8018. Doi: 10.1016/j.oceaneng.2018.07.040.

[10] Zubowicz, T. Marine autonomous surface ship - control system configuration [Text] / T. Zubowicz, K. Armiński, A. Witkowska, R. Śmierzchalski // IFAC-PapersOnLine. - 2019. - V. 52, I. 8. - P. 409415. ISSN 2405-8963. Doi: 10.1016/j.ifacol.2019.08.100.

[11] Budashko, V. V. Physical model of degradation effect by interaction azimuthal flow with hull of ship [Text] / V. V. Budashko, V. V. Nikolskyi, O. A. Onishchenko, S. N. Khniunin // Proceeding Book of International conference on engine room simulators (ICERS12). Istanbul, Istanbul Technical University, Maritime Faculty, 2015. - P. 4953. ISBN: 978-605-01-0782-1. Aviable at: IWwW/ URL: http://www.maritime.itu.edu.tr/icers12/program.htm.

[12] Tran, D.-D. Thorough state-of-the-art analysis of electric and hybrid vehicle powertrains: Topologies and integrated energy management strategies [Text] / D.-D. Tran, M. Vafaeipour, M. E. Baghdadi, R. Barrero, J. V. Mierlo, O. Hegazy // Renewable and Sustainable Energy Reviews. - 2019. - Art. 109596. ISSN 1364-0321. Doi: 10.1016/j.rser.2019.109596.

[13] Babicheva, T.S. The Use of Queuing Theory at Research and Optimization of Traffic on the Signal-controlled Road Intersections [Text] / T.S. Babicheva // Procedia Computer Scienceю - 2015. - V. 55. - P. 469-478. ISSN 1877-0509. Doi: 10.1016/j.procs.2015.07.016.

[14] Wang, W. A two-stage framework for the optimal design of a hybrid renewable energy system for port application [Text] / W. Wang, Y. Peng, X. Li, Q. Qi, P. Feng, Y. Zhang // Ocean Engineering. - 2019. - V. 191. - Art. 106555. ISSN 0029-8018. Doi: 10.1016/j.oceaneng.2019.106555.

[15] Yang, C. Adaptive real-time optimal energy management strategy based on equivalent factors optimization for plug-in hybrid electric vehicle [Text] / C. Yang, S. Du, L. Li, S. You, Y. Yang, Y. Zhao // Applied Energy. - 2017. - V. 203. - P. 883-896. ISSN 0306-2619. Doi: 10.1016/j.apenergy.2017.06.106.

[16] A. Najafi, B. F. Spencer Adaptive model reference control method for real-time hybrid simulation [Text] / A. Najafi, B. F. Spencer // Mechanical Systems and Signal Processing. - 2019. - V. 132. - P. 183193. ISSN 0888-3270. Doi: 10.1016/j.ymssp.2019.06.023.

[17] Nikolskyi, V. The monitoring system of the Coanda effect for the tensionleg platform's [Text] / V. Nikolskyi, V. Budashko, S. Khniunin // Proceeding Book of International conference on engine room simulators (ICERS12). - Istanbul, Istanbul Technical University, Maritime Faculty, 2015. - P. 45-49. ISBN: 978-605-01-0782-1. Aviable at: IWww/ URL: http://www.maritime.itu.edu.tr/icers12/program.htm.

[18] Budashko, V. Synthesis of the Management Strategy of the Ship Power Plant for the Combined Propulsion Complex [Text] / V. Budashko, V. Shevchenko // 2018 IEEE 5th International Conference on Methods and Systems of Navigation and Motion Control (MSNMC), Kyiv, 16-18 Oct. 2018, Ukraine: IEEE. P. 106-108. Doi: 10.1109/MSNMC.2018.8576266. Режим доступу: $\quad$ IWWW/

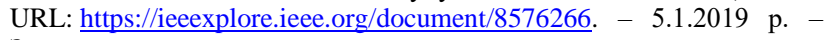
Загол. з екрану. 